\title{
Microsomal triglyceride transfer protein -164 T > C gene polymorphism and risk of cardiovascular disease: results from the EPIC-Potsdam case-cohort study
}

Romina di Giuseppe ${ }^{1 *}$, Sonali Pechlivanis ${ }^{3}$, Eva Fisher ${ }^{4}$, Maria Arregui ${ }^{1}$, Beate Weikert ${ }^{5}$, Sven Knüppel ${ }^{1}$, Brian Buijsse ${ }^{1}$, Andreas Fritsche ${ }^{6}$, Stefan N Willich ${ }^{7}$, Hans-Georg Joost ${ }^{2}$, Heiner Boeing ${ }^{1}$, Susanne Moebus ${ }^{3}$ and Cornelia Weikert ${ }^{1,7}$

\begin{abstract}
Background: The microsomal triglyceride transfer protein (MTTP) is encoded by the MTTP gene that is regulated by cholesterol in humans. Previous studies investigating the effect of MTTP on ischemic heart disease have produced inconsistent results. Therefore, we have tested the hypothesis that the rare allele of the $-164 T>C$ polymorphism in MTTP alters the risk of cardiovascular disease (CVD), depending on the cholesterol levels.

Methods: The -164T > C polymorphism was genotyped in a case-cohort study (193 incident myocardial infarction (MI) and 131 incident ischemic stroke (IS) cases and 1978 non-cases) nested within the European Prospective Investigation into Cancer and Nutrition (EPIC)-Potsdam study, comprising 27548 middle-aged subjects. The Heinz Nixdorf Recall study (30 CVD cases and 1188 controls) was used to replicate our findings.

Results: Genotype frequencies were not different between CVD and CVD free subjects ( $P=0.79$ ). We observed an interaction between the -164T > C polymorphism and total cholesterol levels in relation to future CVD. Corresponding stratified analyses showed a significant increased risk of CVD ( $H R_{\text {additve }}=1.38,95 \% \mathrm{Cl}$ : 1.07 to 1.78) for individuals with cholesterol levels $<200 \mathrm{mg} / \mathrm{dL}$ in the EPIC-Potsdam study. HRadditive was 1.06, 95\% Cl: 0.33 to 3.40 for individuals in the Heinz Nixdorf Recall study. A borderline significant decrease in CVD risk was observed in subjects with cholesterol levels $\geq 200 \mathrm{mg} / \mathrm{dL}$ (HRadditve $=0.77,95 \% \mathrm{Cl}: 0.58$ to 1.03 ) in the EPIC-Potsdam study. A similar trend was observed in the independent cohort ( $\mathrm{HR}_{\text {additve }}=0.60,95 \% \mathrm{Cl}: 0.29$ to 1.25$)$.
\end{abstract}

Conclusions: Our study suggests an interaction between MTTP -164T > C functional polymorphism with total cholesterol levels. Thereby risk allele carriers with low cholesterol levels may be predisposed to an increased risk of developing CVD, which seems to be abolished among risk allele carriers with high cholesterol levels.

Keywords: Epidemiology, Genetics, Myocardial infarction, Ischemic stroke, Cholesterol, Additive interaction

\footnotetext{
* Correspondence: romina.digiuseppe@dife.de

'Department of Epidemiology, German Institute of Human Nutrition

Potsdam-Rehbrücke, Nuthetal, Germany

Full list of author information is available at the end of the article
} 


\section{Background}

The microsomal triglyceride transfer protein (MTTP), a lipid transfer protein encoded by the MTTP gene, is located in the luminal side of the endoplasmic reticulum $[1,2]$. It plays an important role in the assembly and secretion of apolipoproteins B (ApoB) containing lipoproteins as chylomicrons in the intestine, and of very low density lipoproteins (VLDLs) in the liver [3-5]. In turn, chylomicrons transport exogenous lipids to cells, while VLDLs carry endogenous triglycerides through the bloodstream. Thus, considering the important role played by $M T T P$ in fat absorption and lipoprotein regulation, several studies have been conducted on MTTP promoter polymorphisms [6-24].

Three polymorphisms of the MTTP gene (4q24), Ile128Thr (rs3816873), -164T > C (rs1800804), and $-493 \mathrm{G}>\mathrm{T}$ (rs1800591), have been described which are in complete linkage disequilibrium [6]. The rare alleles of these polymorphisms have been reported to decrease plasma lipoprotein-lipid levels [6-14] and some features of metabolic syndrome [16-19]. However, conflicting or negative findings have been reported by others [20-26]. The same inconsistent results have been published with regard to coronary heart disease (CHD) [7,24-26]. Two studies reported null findings $[23,24]$. In contrast, in the INTERGENE [26], ULSAM and WOSCOPS [7] studies homozygosity for the $-164 \mathrm{C}$ and the $-493 \mathrm{~T}$ alleles was associated with increased risk of ischemic heart disease (IHD) though, in the latter, concomitantly to a decrease in total plasma cholesterol [7]. Nevertheless, considered the reduced expression of the MTTP gene in carriers of the rare alleles [26], it is reasonable to expect lower cholesterol levels which have previously been shown to regulate MTTP gene expression [27,28]. Also, it is likely to assume an interaction between the genotype of MTTP and cholesterol levels [19] in affecting the risk of CHD.

Therefore, in the framework of the European Prospective Investigation into Cancer and Nutrition (EPIC)-Potsdam study we investigated the association of the $-164 \mathrm{~T}>\mathrm{C}$ variant, used as proxy for the three loci, with cardiovascular disease (CVD), myocardial infarction (MI) and ischemic stroke (IS) and the presence of an interaction between $-164 \mathrm{~T}>\mathrm{C}$ polymorphism and total cholesterol in relation to CVD (MI and IS). We hypothesized that in carriers of the MTTP -164 C-allele lower cholesterol levels are associated with increased susceptibility to MI and IS.

\section{Methods}

\section{Ethics statement}

\section{EPIC-Potsdam study}

The Ethics Committee of the Medical Association of the State of Brandenburg approved the study procedures and a written informed consent was obtained from all participants.

\section{Heinz Nixdorf Recall study}

The study was approved by the local ethics committees, was conducted in accordance with German Good Epidemiologic Practice (GEP) including extended quality management procedures and re-certifications according to DIN ISO 9001:2001. Informed consent was obtained from all participants. Information on genotype, sex, age, diabetes, anti-hyperlipidemic drugs and CVD was available for up to 1513 of 4814 participants.

\section{Study population \\ EPIC-Potsdam study}

Between 1994 and 1998, as a part of the large-scale European prospective cohort study EPIC, the EPICPotsdam study enrolled from the general population 16 644 women (aged 35 to 65 years) and 10904 men (aged 40 to 65 years for), for a total of 27548 participants [29].

At baseline, self-administered questionnaires on diet and lifestyle, PC-guided interviews with additional questions on prevalent diseases, blood pressure and anthropometric measurements were collected following standard procedures [30].

Every two years, information on incident diseases and changes in lifestyle are collected by self-administered questionnaires [31], with response rates during follow-up exceeding $90 \%$ at all occasions.

A case-cohort study consisting of all incident cases identified during a mean follow-up of $8 \pm 2.2$ years [32] and a subcohort of 2500 individuals randomly selected from the EPIC-Potsdam cohort [33], was used to assess the association of the $-164 \mathrm{~T}>\mathrm{C}$ variant with $\mathrm{CVD}$ risk (including both MI and IS).

With this type of study, the results are expected to be representative of the entire cohort [34,35]. After the exclusion of participants with prevalent MI and stroke at the baseline, 269 individuals with incident MI and 246 individuals with incident stroke were identified (199 IS, 41 hemorrhagic strokes, and 6 strokes with undefined pathogenesis). Among the subcohort, non-ischemic strokes were not considered as cases, while for individuals who experienced both MI and IS only the first event was considered [36]. After exclusion of prevalent CVD and missing follow-up dates, 2368 participants remained to be in the subcohort. After further exclusion of subjects with a history of diabetes at the baseline and/or treated with anti-hyperlipidemic drugs, and those with missing MTTP genotype, biochemical or covariates data the final casecohort consisted of 2302 individuals (324 CVD cases: 193 MI and 131 IS, and 1978 non-cases). Among CVD cases, 37 were part of the subcohort.

\section{Heinz Nixdorf Recall study}

For the replication we analyzed data from the Heinz Nixdorf Recall (Risk Factors, Evaluation of Coronary Calcium and 
Lifestyle) study comprising 4814 participants aged 45-75 years. The participants were randomly selected from registration lists of the densely populated Ruhr metropolitan area in Germany between 2000 and 2003. The rationale and design of the study have been described in detail [37]. Between 2006 and 2008 incident cases were identified during the 5 -year follow-up examination.

The genotyping of the MTTP SNP -I128T (rs3816873) was already available in a random selected sample of $n=1$ 513 Heinz Nixdorf Recall participants out of 4 814. After exclusion of participants with a history of CVD and/or diabetes at baseline and/or treated with anti-hyperlipidemic drugs, the final replication cohorts consisted of $n=1218$ individuals (30 CVD and 1188 non-cases).

\section{Ascertainment of CVD EPIC-Potsdam study}

As described elsewhere [32], all possible cases of MI or stroke were identified by self-report or by death certificate in one of the four follow-up questionnaires and further verified by contacting the patients' attending physician or by review of death certificates according to WHO MONICA criteria.

\section{Heinz Nixdorf Recall study}

Incident CVD $(\mathrm{n}=30)$ included fatal and nonfatal MI $(n=24)$ and other CVD $(n=6)$, were identified.

Primary endpoints for this study were based on unequivocally documented incident coronary events that met predefined study criteria. We considered a myocardial infarction event based on symptoms, signs of electrocardiography, and enzymes (levels of creatine kinase (CK-MB)) as well as troponin T or I, and necropsy as 1) non-fatal acute myocardial infarction and 2) coronary death, which occurred between the baseline examination and five years after study entry $[38,39]$. For all primary study endpoints, hospital and nursing home records including electrocardiograms, laboratory values, and pathology reports were collected. For deceased subjects, death certificates were collected and interviews with general practitioners, relatives and eyewitnesses were undertaken if possible. Medical records were obtained in 100\% of all reported endpoints. An external criteria and endpoint committee blinded for conventional risk factor status and CAC scores reviewed all documents and classified the endpoints thereafter. Due to the small number of cases only total CVD were considered for the replication analysis.

\section{Other measurements}

Prevalent diabetes mellitus was identified by a physician and based on self-reported medical diagnoses, medication records and dieting behavior. Prevalent hypertension was defined as follows: systolic blood pressure $\geq 140 \mathrm{~mm} \mathrm{Hg}$ or diastolic blood pressure $\geq 90 \mathrm{~mm} \mathrm{Hg}$ or self-reporting of a diagnosis or use of antihypertensive medication. Education, lifestyle characteristics (including alcohol consumption), regular sport activity and smoking history were assessed at baseline by trained interviewers during a PCguided interview. Trained personnel took anthropometric and blood pressure measurements.

\section{Biochemical analyses \\ EPIC-Potsdam study}

At baseline, $30 \mathrm{ml}$ of venous blood was taken from the respected participant (non-fasting or fasting blood) and, after fractionation into serum, plasma (collected on citrate, $10 \%$ of total volume), leukocytes, and erythrocytes immediately stored at $-196^{\circ}$ in liquid nitrogen [31]. All biomarkers were determined in 2007 in the Department of Internal Medicine, University of Tübingen. Plasma glucose, high-density lipoprotein cholesterol (HDL), total cholesterol and triglycerides were measured with an automatic analyzer (ADVIA 1650, Siemens Medical Solutions, Erlangen, Germany). LDL-cholesterol was calculated using Friedewald's formula [40]. To account for citrate's dilution factor concentrations of total, HDL-, LDL-cholesterol and triglycerides were multiplied by 1.1 .

\section{Heinz Nixdorf Recall study}

At baseline, plasma cholesterol levels were measured with an automatic analyzer (ADVIA 1650, Siemens Medical Solutions, Erlangen, Germany).

\section{Genetic analyses \\ EPIC-Potsdam study}

DNA extraction was performed using a commercial kit (Qiagen, Hilden, Germany). In 2009 at the Max Delbrück Center for Molecular Medicine, Berlin, Germany, the MTTP SNP -164T >C (rs1800804) was genotyped by TaqMan technology (Applied Biosystems, Foster City, CA, USA) using $5 \mathrm{ng}$ of whole-genome amplified DNA per sample. The call rate for the SNP assay exceeded $98 \%$.

\section{Heinz Nixdorf Recall study}

Lymphocyte DNA was isolated from EDTA anti-coagulated venous blood by a Chemagic Magnetic Separation Module I (Chemagen, Baesweiler, Germany). The MTTP SNP I128T (rs3816873) was genotyped using four different platforms: Illumina Hap300, Illumina Hap550, Illumina Human660W-Quad and Illumina HumanOmni1-Quad. The call rate for this SNP was 99.9\%.

\section{Statistical analysis}

For both EPIC-Potsdam and Heinz Nixdorf Recall studies statistical analyses were performed with the use of SAS software package, release 9.2 (SAS Institute, Cary, NC). 


\section{EPIC-Potsdam study}

Data on triglyceride measurements were transformed into natural logarithms to reduce skewness and data were reported as geometric means and 95\% confidence interval $(\mathrm{CI})$.

The deviation from Hardy-Weinberg equilibrium (HWE) was measured using the $\chi^{2}$ test.

The HWE was tested in the subcohort. Age and sex adjusted analysis of variance was used to describe general characteristics according to $-164 \mathrm{~T}>\mathrm{C}$ genotype. Data were reported as means and standard error (SE). P for trend was calculated from age and sex adjusted linear regression model. To investigate the impact of total cholesterol on the associations between genotype and CVD we performed stratified analyses according to low $(<200 \mathrm{mg} / \mathrm{dL})$ and borderline-high/high $(\geq 200 \mathrm{mg} / \mathrm{dL})$ cholesterol levels as defined in the Adult Treatment Panel III (ATP III) report [41]. Multiplicative interaction between cholesterol levels and genotype as well as sex and genotype in relation to CVD was tested with crossproduct term. As a measure of additive interaction between cholesterol levels and genotype we further calculated the Synergy Index (SI) and the relative excess risk due to interaction (RERI) and their 95\% confidence interval (CI) [42], as suggested by Rothman [43]. SI $>1$ and RERI $>0$ suggest a positive interaction (superadditive effect); $\mathrm{SI}<1$ and RERI $<0$ suggest a negative interaction (subadditive effect); $\mathrm{SI}=1$ and RERI $=0$ suggest absence of interaction.

Both the multiplicative and additive interactions were also tested for triglycerides, HDL- and LDL-cholesterol. The choice of the cut-off values for these biomarkers was also based on the ATP III criteria (lower and higher than $130 \mathrm{mg} / \mathrm{dL}$ for LDL-cholesterol; lower and higher than 40 $\mathrm{mg} / \mathrm{dL}$ and lower and higher than $50 \mathrm{mg} / \mathrm{dL}$ for HDLcholesterol, respectively, in men and women; lower and higher than $150 \mathrm{mg} / \mathrm{dL}$ for triglycerides) [41].

Cox proportional-hazard regression modified according to the Prentice method [34] was used to compute the age and sex adjusted hazard ratio (HR) and 95\% CI for the associations between MTTP $-164 \mathrm{~T}>\mathrm{C}$ and risk of MI, IS and total CVD (combined endpoints). In the counting processes age was the underlying time variable with "entry time" defined as age at baseline and "exit time" as age at CVD event (MI or IS) or censoring. Associations between MTTP $-164 \mathrm{~T}>\mathrm{C}$ and CVDs were tested in three models: additive, dominant and recessive. Furthermore, competing risk analyses were performed to test whether the associations of MTTP -164T > C with cardiovascular events differed between MI and IS, as described by Lunn and McNeil [44].

The power to detect an association between the MTTP $-164 \mathrm{~T}>\mathrm{C}$ SNP and CVDs (MI, IS and combined endpoints) was computed with Quanto (http://hydra.usc.edu/
$\mathrm{GxE} /$ ) [45], in relation to a desirable power $=80 \%$, assuming $\alpha=0.05$ and a disease prevalence of $3.1 \%$ for CVD $(n=847)$, $2.0 \%$ for MI $(\mathrm{n}=544)$ and $1.1 \%$ for IS $(\mathrm{n}=303)$, reflecting the baseline prevalence data in the EPIC-Potsdam population. The detectable odds ratio per risk allele equals 1.30 , 1.39 and 1.47 , respectively for CVD, MI and IS.

\section{Heinz Nixdorf Recall study}

Cox proportional-hazard regression was used to compute the age and sex adjusted hazard ratio (HR) and 95\% CI for the associations between MTTP -I128T and risk of total CVD. Associations between MTTP -I128T and CVDs were tested using the additive model.

\section{Results}

\section{General characteristics}

The genotype distribution of the $-164 \mathrm{~T}>\mathrm{C}$ and $-\mathrm{I} 128 \mathrm{~T}$ SNPs followed the HWE $(P=0.37$ and $P=0.71$, respectively for the EPIC-Potsdam subcohort and for the replication Heinz Nixdorf Recall study). There were 1 114, 758 and 143 subjects with genotypes TT, CT, CC respectively (738 men and 1277 women) observed in the subcohort. The $\mathrm{C}$ allele frequency was 0.26 for both studies. According to $-164 \mathrm{~T}>\mathrm{C}$ genotype, age- and sex-adjusted baseline characteristics of subjects who did or did not develop cardiovascular events during the follow-up period are shown in Table 1. In particular, subjects with incident CVD ( $\mathrm{n}=324 ; 193$ incident MI; 131 incident IS) were men, older, smokers and with a lower educational level than individuals who remained free of CVD $(n=1978)$ during a mean follow-up of 8.2 years. Furthermore, they had a higher prevalence of abdominal obesity and hypertension, slightly higher total and low density lipoprotein- (LDL-) and lower HDL-cholesterol levels (Table 1). According to genotype no significant differences in central obesity, obesity and hypertension and socio-demographic characteristics were observed in subjects with or without CVD (Table 1). In contrast, opposite trends were observed for total-, LDL-cholesterol and triglyceride levels. In the group free of CVD carriers of the C-allele showed slightly higher total- and LDL-cholesterol levels $\left(\mathrm{P}_{\text {trend }}=0.036\right.$ and $\mathrm{P}_{\text {trend }}=0.026$, respectively). In the group of CVD carriers of the $\mathrm{C}$-allele showed lower triglyceride $\left(\mathrm{P}_{\text {trend }}=\right.$ 0.016) along with slight lower total-cholesterol levels $\left(P_{\text {trend }}=0.033\right)($ Table 1$)$.

\section{Association between MTTP-164T > C polymorphism and incident CVD}

The association between the MTTP $-164 \mathrm{~T}>\mathrm{C}$ polymorphism and CVD events was tested also for MI and IS separately, taking into consideration the additive, dominant and recessive models (Table 2). Since there were no sex differences in the association between MTTP -164T >C and CVD (P for interaction $=0.86$ ), we combined men and 
Table 1 Baseline characteristics of subjects according to cardiovascular disease status and MTTP -164 T > C genotype in EPIC-Potsdam study

\begin{tabular}{|c|c|c|c|c|c|c|c|c|c|c|}
\hline & \multirow[b]{2}{*}{ All CVD free } & \multicolumn{3}{|c|}{ CVD free by genotype } & \multirow[b]{2}{*}{$P$ for trend ${ }^{a}$} & \multirow[b]{2}{*}{ All CVD } & \multicolumn{3}{|c|}{ CVD by genotype } & \multirow[b]{2}{*}{$P$ for trend ${ }^{a}$} \\
\hline & & TT & $\mathrm{CT}$ & $\mathrm{CC}$ & & & TT & $\mathrm{CT}$ & $\mathrm{CC}$ & \\
\hline$n$ & 1978 & 1096 & 742 & 140 & & 324 & 178 & 126 & 20 & \\
\hline age, yrs & $49.8 \pm 0.2$ & $49.5 \pm 0.3$ & $49.2 \pm 0.3$ & $49.4 \pm 0.7$ & 0.543 & $54.9 \pm 0.5$ & $56.1 \pm 0.6$ & $54.1 \pm 0.7$ & $56.6 \pm 1.7$ & 0.223 \\
\hline Men, \% & 36.8 & 36.7 & 35.3 & 35.0 & 0.687 & 58.5 & 64.3 & 60.9 & 69.4 & 0.654 \\
\hline Abdominal obesity, \% ${ }^{\mathrm{b}}$ & 21.4 & 20.9 & 20.3 & 18.8 & 0.567 & 26.9 & 32.2 & 30.9 & 30.0 & 0.837 \\
\hline Obesity, \% ${ }^{c}$ & 14.9 & 14.5 & 15.5 & 9.7 & 0.134 & 18.4 & 19.9 & 19.4 & 19.6 & 0.975 \\
\hline Hypertension, \% & 47.6 & 45.6 & 44.7 & 43.7 & 0.592 & 60.3 & 70.8 & 68.3 & 49.0 & 0.114 \\
\hline Current smokers, \% & 21.4 & 21.2 & 22.5 & 21.4 & 0.957 & 39.7 & 35.7 & 31.6 & 47.9 & 0.264 \\
\hline High education, \% & 41.7 & 44.2 & 38.7 & 44.4 & 0.978 & 34.1 & 31.8 & 30.3 & 36.1 & 0.699 \\
\hline High sport activity, \% & 24.8 & 25.2 & 24.4 & 27.5 & 0.230 & 19.9 & 18.0 & 13.0 & 23.5 & 0.534 \\
\hline Cholesterol, mg/dL & $191 \pm 0.9$ & $189 \pm 1.2$ & $192 \pm 1.5$ & $195 \pm 3.4$ & 0.036 & $198 \pm 2.3$ & $210 \pm 3.3$ & $199 \pm 3.9$ & $199 \pm 9.7$ & 0.033 \\
\hline HDL-cholesterol, mg/dL & $52 \pm 0.3$ & $52 \pm 0.4$ & $52 \pm 0.5$ & $52 \pm 1.2$ & 0.840 & $50 \pm 0.8$ & $50 \pm 1.1$ & $51 \pm 1.3$ & $47 \pm 3.2$ & 0.575 \\
\hline LDL-cholesterol, mg/dL & $114 \pm 0.8$ & $112 \pm 1.0$ & $115 \pm 1.2$ & $116 \pm 2.8$ & 0.026 & $120 \pm 1.9$ & $128 \pm 2.7$ & $121 \pm 3.2$ & $129 \pm 7.9$ & 0.305 \\
\hline Triglyceride, mg/dL & $107(105-110)$ & $105(101-108)$ & $108(104-112)$ & $\begin{array}{c}114 \\
(104-124)\end{array}$ & 0.087 & $118(111-125)$ & $131(120-144)$ & $116(104-129)$ & 99 (76-129) & 0.016 \\
\hline Alcohol consumption, g/day & $8.0(7.5-8.5)$ & $8.2(7.6-8.9)$ & $7.5(6.8-8.2)$ & $9.5(7.6-11.7)$ & 0.871 & $5.9(5.1-6.9)$ & $5.5(4.3-7.0)$ & $5.8(4.4-7.6)$ & $3.9(2.0-7.9)$ & 0.663 \\
\hline
\end{tabular}

${ }^{a}$ Determined from linear regression model adjusted for age and sex (where appropriate) in reference to CVD free and CVD by genotype. Age was adjusted for sex. Sex was adjusted for age. ${ }^{b}$ Abdominal obesity was defined according to the ATP III criteria [41] based on the following waist circumference cut-off points: men $\geq 102 \mathrm{~cm}$ and women $\geq 88 \mathrm{~cm}$.

'Obesity was defined as $\mathrm{BMI} \geq 30 \mathrm{~kg} / \mathrm{m}^{2}$.

${ }^{\mathrm{d}}$ Geometric means and $95 \%(\mathrm{Cl})$ all such values. 


\begin{tabular}{|c|c|c|c|c|c|c|}
\hline & \multicolumn{3}{|c|}{ Cholesterol $<200 \mathrm{mg} / \mathrm{dL}$} & \multicolumn{3}{|c|}{ Cholesterol $\geq \mathbf{2 0 0 ~} \mathrm{mg} / \mathrm{dL}$} \\
\hline & \multicolumn{3}{|c|}{$\mathrm{HR}(95 \% \mathrm{Cl})^{\mathrm{a}}$} & \multicolumn{3}{|c|}{$\mathrm{HR}(95 \% \mathrm{Cl})^{\mathrm{a}}$} \\
\hline & CVD & $\mathrm{Ml}$ & IS & CVD & $\mathrm{Ml}$ & IS \\
\hline Cases, $\mathrm{n}$ & 139 & 69 & 70 & 185 & 77 & 40 \\
\hline C allele & $1.38(1.07-1.78)$ & $1.19(0.82-1.72)$ & $1.60(1.16-2.20)$ & $0.77(0.58-1.03)$ & $0.76(0.54-1.07)$ & $0.77(0.48-1.23)$ \\
\hline Padditive & 0.014 & 0.353 & 0.004 & 0.075 & 0.113 & 0.273 \\
\hline Dominant & $1.76(1.22-2.54)$ & $1.41(0.85-2.33)$ & $2.22(1.35-3.64)$ & $0.67(0.48-0.94)$ & $0.65(0.43-0.97)$ & $0.69(0.40-1.18)$ \\
\hline$P_{\text {dominant }}$ & 0.002 & 0.186 & 0.002 & 0.021 & 0.036 & 0.172 \\
\hline Recessive & $0.73(0.31-1.69)$ & $0.71(0.21-2.39)$ & $0.75(0.25-2.27)$ & $0.98(0.53-1.82)$ & $0.99(0.47-2.06)$ & $0.93(0.33-2.66)$ \\
\hline$P_{\text {recessive }}$ & 0.458 & 0.580 & 0.616 & 0.948 & 0.969 & 0.892 \\
\hline
\end{tabular}

${ }^{a}$ Adjusted for age and sex.

women in all analyses. After adjustment for age and sex, Cox regression analyses revealed no significant association between the $-164 \mathrm{~T}>\mathrm{C}$ variant and CVD risk considering the additive $\left(\mathrm{HR}_{\text {additive }}=1.04,95 \% \mathrm{CI}: 0.86\right.$ to $1.25 ; \mathrm{P}=$ $0.714)$, dominant $\left(\mathrm{HR}_{\mathrm{CT}+\mathrm{CC} \text { vs } \mathrm{TT}}=1.09,95 \% \mathrm{CI}: 0.85\right.$ to 1.39; $\mathrm{P}=0.505)$ and recessive $\left(\mathrm{HR}_{\mathrm{CC}}\right.$ vs $\mathrm{CT}+\mathrm{TT}=0.90,95 \%$ CI: 0.55 to $1.46 ; \mathrm{P}=0.662$ ) models. Nevertheless, the multiplicative and additive interactions between the $-164 \mathrm{~T}$ $>\mathrm{C}$ polymorphism and total cholesterol (dichotomous) in relation to CVD risk were significant and in the same negative direction ( $\beta$ multiplicative interaction $=-0.55 \pm 0.19$; $\mathrm{P}=0.004 ; \mathrm{SI}_{\text {additive interaction }}=0.31,95 \% \mathrm{CI}$ : 0.16 to 0.62 and RERI $_{\text {additive interaction }}=-1.44,95 \%$ CI: -2.37 to -0.51$)$.

Stratified analyses according to low $(<200 \mathrm{mg} / \mathrm{dL})$ and borderline-high/high $(\geq 200 \mathrm{mg} / \mathrm{dL})$ cholesterol levels showed significant positive associations between MTTP $-164 \mathrm{~T}>\mathrm{C}$ and CVD in subjects with cholesterol levels $<200 \mathrm{mg} / \mathrm{dL}$, considering both the additive $\left(\mathrm{HR}_{\text {additive }}=\right.$ 1.38, 95\% CI: 1.07 to $1.78 ; \mathrm{P}=0.014$ ) and the dominant models $\left(\mathrm{HR}_{\mathrm{CT}+\mathrm{CC}}=1.76,95 \% \mathrm{CI}: 1.22-2.54 ; \mathrm{P}=0.002\right)$ (Table 2). Analyzing MI and IS separately, the associations seemed to be stronger for stroke $\left(\mathrm{HR}_{\text {additive }}=1.60,95 \% \mathrm{CI}\right.$ : 1.16 to $2.20, \mathrm{P}=0.004 ; \mathrm{HR}_{\text {dominant }}=2.22,95 \% \mathrm{CI}: 1.35$ to $3.64, \mathrm{P}=0.002)$ than for $\mathrm{MI}\left(\mathrm{HR}_{\text {additive }}=1.19,95 \% \mathrm{CI}\right.$ : 0.82 to $1.72, \mathrm{P}=0.353 ; \mathrm{HR}_{\text {dominant }}=1.41,95 \% \mathrm{CI}: 0.85$ to $2.33, \mathrm{P}=0.186)$. However, results from the competing risk analysis (IS versus MI) provided a Wald test $\mathrm{P}$ value equal to 0.28 and 0.20 , respectively, for the additive and dominant model. Further adjustment for other CVD risk factors (i.e. body mass index, waist circumference, prevalent hypertension, sport activity and alcohol consumption) led to similar HRs depicted in Table 2 (data not shown).

In subjects with cholesterol levels $\geq 200 \mathrm{mg} / \mathrm{dL}$ we observed a borderline inverse association between MTTP $-164 \mathrm{~T}>\mathrm{C}$ and $\mathrm{CVD}$ in the additive model $\left(\mathrm{HR}_{\text {additive }}=\right.$ $0.77,95 \% \mathrm{CI}: 0.58$ to $1.03, \mathrm{P}=0.075)$ and significant relationships in the dominant model $\left(\mathrm{HR}_{\text {dominant }}=0.67,95 \%\right.$
CI: 0.48 to $0.94, \mathrm{P}=0.021 ; \mathrm{HR}_{\text {dominant }}=0.65,95 \% \mathrm{CI}: 0.43$ to $0.97, \mathrm{P}=0.036$, respectively, for $\mathrm{CVD}$ and $\mathrm{MI}$ ) (Table 2).

We performed additional analyses to test both the multiplicative and additive interactions for triglycerides, HDL- and LDL-cholesterol concentrations. The interactions between $M T T P /$ triglycerides and MTTP/HDLcholesterol in relation to CVD were not significant $(\mathrm{P}=$ 0.18 and $P=0.11$, respectively), whereas they were significant and in the same direction as those found for total cholesterol when LDL-cholesterol was analyzed (multiplicative interaction: $\mathrm{P}=0.023 ; \mathrm{SI}_{\text {additive interaction }}=0.33$;

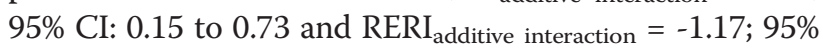
CI: -2.01 to -0.33$)$. Stratified analysis according to the 2 LDL-cholesterol categories $(<130$ and $\geq 130 \mathrm{mg} / \mathrm{dL})$ showed an increased CVD $\left(\mathrm{HR}_{\text {additive }}=1.24 ; 95 \%\right.$ CI: 0.98 to $1.56 ; \mathrm{HR}_{\text {dominant }}=1.51 ; 95 \% \mathrm{CI}: 1.09$ to 2.08$)$ and IS risk $\left(\mathrm{HR}_{\text {additive }}=1.30 ; 95 \% \mathrm{CI}: 0.96\right.$ to $1.75 ; \mathrm{HR}_{\text {dominant }}=1.66$; 95\% CI: 1.07 to 2.57 ) in the low LDL group when MTTP was considered in a dominant fashion. A decreased CVD $\left(\mathrm{HR}_{\text {additive }}=0.80 ; 95 \% \mathrm{CI}: 1.58\right.$ to $1.09 ; \mathrm{HR}_{\text {dominant }}=0.69$; 95\% CI: 0.47 to 1.00$)$ and $\mathrm{MI}\left(\mathrm{HR}_{\text {additive }}=0.74 ; 95 \% \mathrm{CI}\right.$ : 0.51 to $1.07 ; \mathrm{HR}_{\text {dominant }}=0.62 ; 95 \% \mathrm{CI}$ : 0.39 to 0.96 ) risk was observed, instead, in the high LDL group, always in a dominant fashion (data not shown).

In the replication cohort we did observe a trend toward a decreased CVD risk in individuals with cholesterol levels higher than $200 \mathrm{mg} / \mathrm{dL} \quad\left(\mathrm{HR}_{\text {additive }}=0.60\right.$, $95 \% \mathrm{CI}: 0.29$ to $1.25 ; \mathrm{P}=0.17)$. No association was observed in the other strata $(<200 \mathrm{mg} / \mathrm{dL})\left(\mathrm{HR}_{\text {additive }}=\right.$ 1.06, $95 \%$ CI: 0.33 to 3.40 ; $\mathrm{P}=0.92$ ).

\section{Discussion}

In this study, we anticipated an interaction between total cholesterol levels and the MTTP $-164 \mathrm{~T}>\mathrm{C}$ polymorphism with regard to the CVD risk. The presence of a statistically significant interaction confirmed our hypothesis and indicated carriers of the $\mathrm{C}$ allele of the MTTP $-164 \mathrm{~T}>\mathrm{C}$ 
polymorphism with plasma total cholesterol levels lower than $200 \mathrm{mg} / \mathrm{dL}$ had an increased risk of CVD. The association seemed to be stronger for IS than for MI, but differences in the associations were not supported by competing risk analysis. Conversely, the MTTP -164 Callele showed a lower CVD, and MI, risk in participants with cholesterol levels higher than $200 \mathrm{mg} / \mathrm{dL}$. Similar relationships were observed considering LDL-cholesterol with levels lower and higher than $130 \mathrm{mg} / \mathrm{dl}$ suggesting that LDL is the driving cholesterol component. However, the value of LDL levels seems to be limited as they had to be estimated based on the Friedewald formula [46]. In fact further studies are needed to replicate these findings.

The association between MTTP -I128T polymorphisms and CVD risk observed in the replication cohort showed a similar trend within the strata of cholesterol levels higher than $200 \mathrm{mg} / \mathrm{dL}$. However, considering that the number of cases in the Heinz Nixdorf Recall study is small further replication studies are needed. To our knowledge, this is the first prospective study showing such an effect of MTTP on risk of IS.

With regard to the association between the MTTP -164T > C polymorphism and cholesterol levels, previous studies observed inconsistent results. Few studies reported a slight cholesterol lowering effect of the rare alleles of the MTTP promoter polymorphisms [7,10]. Ledmyr et al. investigated the association between the MTTP $-493 \mathrm{G} / \mathrm{T}$ polymorphism and cholesterol in both healthy and hypercholesterolemic individuals, and observed decreased levels of total cholesterol in carriers of the $-493 \mathrm{~T}$ variant $[7,10]$. Furthermore, Phillips et al. in a small study including 82 patients with type 2 diabetes mellitus (T2DM) of a Caucasian population found that the subjects heterozygous for the $-493 \mathrm{G} / \mathrm{T}$ had lower LDL-cholesterol and, in the postprandial phase, higher apoB48 levels in the VLDL fraction. The authors suggested that the $-493 \mathrm{G} / \mathrm{T}$ polymorphism seemed to confer protection against atherosclerosis in T2DM patients [12]. In contrast, Jou et al. observed that total cholesterol, LDL-, and non HDL-cholesterol levels were higher according to the rare allele of the MTTP -493 G/T polymorphism when disease free young African Americans were investigated [19,20]. Further, Lundahl et al. observed lower serum triglyceride levels in subjects affected by familial hypercholesterolemia and homozygous for the rare allele of the MTTP -493 G/T genotype [8].

Overall, these studies seem to suggest that MTTP regulates lipids differently in the presence or absence of disease, although the occurrence of a possible interaction between the LDL receptor and the MTTP genes is not excluded $[7,14]$. Our results seem to be in line with these hypotheses. On one hand we observed slightly higher total and LDL-cholesterol levels in subjects free of CVD and homozygous for the rare $-164 \mathrm{C}$ allele, and on the other, lower total cholesterol and triglyceride levels according to the rare allele of the MTTP $-164 \mathrm{~T}>\mathrm{C}$ polymorphism in the group of future CVD cases.

It has been shown that the $\mathrm{C}$-allele of the MTTP-164 $\mathrm{T}>\mathrm{C}$ polymorphism is homologous to a putative sterol response element (SRE) binding site and as such confers a reduced MTTP expression [26-28]. These findings come from an experimental study in which Hagan et al. demonstrated that human MTTP promoter activity is upregulated by cholesterol [27]. The mechanism based on which cholesterol regulates MTTP gene expression is linked to the presence of a modified SRE in the MTTP promoter [27]. When cholesterol levels are low, the sterol regulatory element binding protein (SREBP) acts as transcription factor, binds to the SRE thereby inhibiting MTTP gene expression [28]. In contrast, in presence of cholesterol the modified SRE likely binds a new SREBP family member thus up-regulating MTTP expression [27,28]. These observations suggest that MTTP gene expression is differently regulated by high and low cholesterol levels.

Despite the lack of significant associations between the $-493 \mathrm{G}>\mathrm{T}$ or $-164 \mathrm{~T}>\mathrm{C}$ single nucleotide polymorphisms (SNPs), coronary heart disease and blood lipids observed in two previous studies [24,25], recently Aminoff et al. put forward that carriers of the rare -164C allele are at increased risk of IHD [26]. They substantiated their findings by showing in vivo that the presence of the rare alleles of the $-493 \mathrm{G}>\mathrm{T}$ and $-164 \mathrm{~T}>\mathrm{C}$ SNPs confer lower MTTP transcription in the heart, liver and macrophage. This mechanism, in turn, by causing the lipid accumulation in the heart would provoke an increased IHD risk. Indeed, our findings are in line with those of Aminoff et al. though they concluded that the increased IHD risk observed according to the $-164 \mathrm{C}$ variant was independent of plasma lipids. As mentioned above, because human MTTP promoter activity is positively regulated by cholesterol [27], it is reasonable to assume that subjects with low cholesterol levels have, in general, a lower MTTP gene expression. Thus, in this low risk group carriers of the $-164 \mathrm{C}$ variant, compared to carriers of the common allele, might be at increased CVD because of their lower MTTP gene expression. At the same time, if one would consider the observed associations as those mimicking MTTP inhibitors, then these findings could further highlight the concerns expressed by Aminoff et al. regarding the long term side effects MTTP inhibition may generate $[26,47]$.

In contrast, in subjects with higher cholesterol levels we observed a reduced, though borderline significant, CVD risk accordingly to the MTTP gene $-164 \mathrm{C}$ variant. Our findings suggest that there could be an antagonistic (qualitative) interaction between cholesterol levels and MTTP $-164 \mathrm{~T}>\mathrm{C}$ polymorphism. These observations warrant further investigation. 
The main limitation of this study is that the plasma lipoprotein and apolipoprotein levels, which are important in the effect of MTTP in cardiovascular disease, were not measured; our analyses on triglyceride levels were based on both fasting and non-fasting subjects; we estimated the LDL-cholesterol levels based on Friedewald equation. Strength of our study includes its prospective design. Furthermore, all cases of MI and IS were validated by medical records and were derived from a cohort population with a very high follow-up coverage.

\section{Conclusions}

The findings of this study suggest that in the subjects investigated an interaction between MTTP -164T > C functional polymorphism with total cholesterol levels predisposes risk allele carriers with low cholesterol levels to an increased risk of developing CVD, which seems to be abolished among risk allele carriers with high cholesterol levels. However, further studies are warranted in order to shed more light on these complex mechanisms.

\section{Competing interests}

The authors declare that they have no competing interest.

\section{Authors' contributions}

Conceived and designed the research: HGJ CW HB. Acquired the data: EF AM CW HB. Analyzed the data: RdG SP. Interpreted the data: RdG EF BW SK SNW HB CW. Wrote the manuscript: RdG. Critical revision of the article for important intellectual content: SP EF MA BW SK BB AF SNW HGJ HB SM CW. All authors read and approved the final manuscript.

\section{Acknowledgments \\ We are indebted to Wolfgang Fleischhauer for case ascertainment and to Ellen Kohlsdorf for data management. We thank Kathrin Saar and Norbert Hübner for support and discussion. Part of the Heinz Nixdorf Recall genotyping was funded by Celgene, Munich Germany. The authors thank the participants of the Heinz Nixdorf Recall study and the entire community of Heinz Nixdorf Recall investigators and staff for their support and valuable contributions.}

\section{Funding}

The recruitment phase of the EPIC-Potsdam study was supported by the Federal Ministry of Science (01 EA 9401), Germany, and the European Union (SOC 95201408 05F02). The follow-up of the EPIC-Potsdam study was supported by the German Cancer Aid (70-2488-Ha I) and the European Community (SOC 98200769 05F02). The Heinz Nixdorf Recall study was supported by the Heinz Nixdorf Foundation (Germany), the Sarstedt AG \& $\mathrm{Co}$. (Nümbrecht, Germany) concerning laboratory equipment, the German Ministry of Education and Science (BMBF) and the German Research Foundation (DFG) within the program HO 3314_2-1.

The funders had no role in study design, data collection and analysis, the decision to publish or preparation of the manuscript.

\section{Author details}

'Department of Epidemiology, German Institute of Human Nutrition Potsdam-Rehbrücke, Nuthetal, Germany. ${ }^{2}$ Department of Pharmacology, German Institute of Human Nutrition Potsdam-Rehbrücke, Nuthetal, Germany. ${ }^{3}$ Institute for Medical Informatics, Biometry and Epidemiology, University Hospital of Essen, University Duisburg-Essen, Essen, Germany. ${ }^{4}$ Administrative Office of the Commission on Genetic Testing, Robert Koch-Institute, Berlin, Germany. ${ }^{5}$ Agency for Quality in Medicine, Berlin, Germany. ${ }^{6}$ Department of Internal Medicine, Division of Endocrinology, Diabetology, Nephrology, Vascular Disease and Clinical Chemistry, University of Tübingen, Tübingen, Germany. ${ }^{7}$ Institute for Social Medicine, Epidemiology and Health Economics and Chairman, Charité Center 1 for
Humanities and Health Sciences, Charité University Medical Center, Berlin, Germany.

Received: 9 August 2012 Accepted: 23 January 2013

Published: 29 January 2013

\section{References}

1. Wetterau JR, Lin MC, Jamil H: Microsomal triglyceride transfer protein. Biochim Biophys Acta 1997, 1345:136-150.

2. Hussain MM, Iqbal J, Anwar K, Rava P, Dai K: Microsomal triglyceride transfer protein: a multifunctional protein. Front Biosci 2003, 8:s500-s506.

3. White DA, Bennett AJ, Billett MA, Salter AM: The assembly of triacylglycerol-rich lipoproteins: an essential role for the microsomal triacylglycerol transfer protein. Br J Nutr 1998, 80:219-229.

4. Gordon DA, Jamil H: Progress towards understanding the role of microsomal triglyceride transfer protein in apolipoprotein-B lipoprotein assembly. Biochim Biophys Acta 2000, 1486:72-83.

5. Hussain MM, Shi J, Dreizen P: Microsomal triglyceride transfer protein and its role in apoB-lipoprotein assembly. J Lipid Res 2003, 44:22-32.

6. Berthier MT, Houde A, Paradis AM, Couture P, Gaudet D, Després JP, Vohl $\mathrm{MC}$ : Molecular screening of the microsomal triglyceride transfer protein: association between polymorphisms and both abdominal obesity and plasma apolipoprotein B concentration. J Hum Genet 2004, 49:684-690.

7. Ledmyr H, McMahon AD, Ehrenborg E, Nielsen LB, Neville M, Lithell H, MacFarlane PW, Packard CJ, Karpe F, WOSCOPS executive: The microsomal triglyceride transfer protein gene-493T variant lowers cholesterol but increases the risk of coronary heart disease. Circulation 2004, 109:2279-2284.

8. Lundahl B, Leren TP, Ose L, Hamsten A, Karpe F: A functional polymorphism in the promoter region of the microsomal triglyceride transfer protein (MTTP -493G/T) influences lipoprotein phenotype in familial hypercholesterolemia. Arterioscler Thromb Vasc Biol 2000, 20:1784-1788.

9. Lundahl B, Hamsten A, Karpe F: Postprandial plasma ApoB-48 levels are influenced by a polymorphism in the promoter of the microsomal triglyceride transfer protein gene. Arterioscler Thromb Vasc Biol 2002, 22:289-293.

10. Ledmyr H, Karpe F, Lundahl B, McKinnon M, Skoglund-Andersson C, Ehrenborg E: Variants of the microsomal triglyceride transfer protein gene are associated with plasma cholesterol levels and body mass index. J Lipid Res 2002, 43:51-58.

11. St-Pierre J, Lemieux I, Miller-Felix I, Prud'homme D, Bergeron J, Gaudet D, Nadeau A, Despres JP, Vohl MC: Visceral obesity and hyperinsulinemia modulate the impact of the microsomal triglyceride transfer protein $-493 \mathrm{G} / \mathrm{T}$ polymorphism on plasma lipoprotein levels in men. Atherosclerosis 2002, 160:317-324.

12. Phillips C, Mullan K, Owens D, Tomkin GH: Microsomal triglyceride transfer protein polymorphisms and lipoprotein levels in type 2 diabetes. QJM 2004, 97:211-218.

13. García-García AB, González C, Real JT, de Martín Llano JJ, González-Albert V, Civera M, Chaves FJ, Ascaso JF, Carmena R: Influence of microsomal triglyceride transfer protein promoter polymorphism -493 GT on fasting plasma triglyceride values and interaction with treatment response to atorvastatin in subjects with heterozygous familial hypercholesterolaemia. Pharmacogenet Genomics 2005, 15:211-218.

14. Lundahl B, Skoglund-Andersson C, Caslake M, Bedford D, Stewart P, Hamsten A, Packard CJ, Karpe F: Microsomal triglyceride transfer protein -493T variant reduces IDL plus LDL apoB production and the plasma concentration of large LDL particles. Am J Physiol Endocrinol Metab 2006, 290:E739-E745.

15. Karpe F, Lundahl B, Ehrenborg E, Eriksson P, Hamsten A: A common functional polymorphism in the promoter region of the microsomal triglyceride transfer protein gene influences plasma LDL levels. Arterioscler Thromb Vasc Biol 1998, 18:756-761.

16. Rubin D, Helwig U, Pfeuffer M, Schreiber S, Boeing H, Fisher E, Pfeiffer A, Freitag-Wolf S, Foelsch UR, Doering F, Schrezenmeir J: A common functional exon polymorphism in the microsomal triglyceride transfer protein gene is associated with type 2 diabetes, impaired glucose metabolism and insulin levels. J Hum Genet 2006, 51:567-574.

17. Austin MA, Talmud PJ, Luong LA, Haddad L, Day IN, Newman B, Edwards KL, Krauss RM, Humphries SE: Candidate gene studies of the atherogenic lipoprotein phenotype: a sib-pair linkage analysis of DZ women twins. Am J Hum Genet 1998, 62:406-419. 
18. Sposito AC, Gonbert S, Turpin G, Chapman MJ, Thillet J: Common polymorphism in the MTTP promoter attenuates the dyslipidemic and proatherogenic effects of excess body weight. Arterioscler Thromb Vasc Biol 2004, 24:e143.

19. Böhme M, Grallert H, Fischer A, Gieger C, Nitz I, Heid I, Kohl C, Wichmann HE, Illig T, Döring F: MTTP variants and body mass index, waist circumference and serum cholesterol level: association analyses in 7582 participants of the KORA study cohort. Mol Genet Metab 2008, 95:229-232.

20. Juo SH, Han Z, Smith JD, Colangelo L, Liu K: Common polymorphism in promoter of microsomal triglyceride transfer protein gene influences cholesterol, ApoB, and triglyceride levels in young african american men: results from the coronary artery risk development in young adults (CARDIA) study. Arterioscler Thromb Vasc Biol 2000, 20:1316-1322.

21. Juo SH, Colangelo L, Han Z, Smith JD, Liu K: Confirmation of the microsomal triglyceride transfer protein genetic effect on lipids in young African American men from the CARDIA study. Arterioscler Thromb VasC Biol 2003, 23:912-913.

22. Schgoer W, Eller P, Mueller T, Tancevski I, Wehinger A, Ulmer H, Sandhofer A, Ritsch A, Haltmayer M, Patsch JR: The MTTP -493TT genotype is associated with peripheral arterial disease: results from the Linz peripheral arterial disease (LIPAD) study. Clin Biochem 2008, 41:712-716.

23. Okumura K, Imamura A, Murakami R, Takahashi R, Cheng XW, Numaguchi Y, Murohara T: Microsomal triglyceride transfer protein gene polymorphism strongly influences circulating malondialdehyde-modified low-density lipoprotein. Metabolism 2009, 58:1306-1311.

24. Herrmann SM, Poirier O, Nicaud V, Evans A, Ruidavets JB, Luc G, Arveiler D, Bao-Sheng C, Cambien F: Identification of two polymorphisms in the promoter of the microsomal triglyceride transfer protein (MTTP) gene: lack of association with lipoprotein profiles. J Lipid Res 1998, 39:2432-2435.

25. Couture P, Otvos JD, Cupples LA, Wilson PW, Schaefer EJ, Ordovas JM: Absence of association between genetic variation in the promoter of the microsomal triglyceride transfer protein gene and plasma lipoproteins in the Framingham offspring study. Atherosclerosis 2000, 148:337-343.

26. Aminoff A, Ledmyr $H$, Thulin $P$, Lundell $K$, Nunez L, Strandhagen E, Murphy C, Lidberg U, Westerbacka J, Franco-Cereceda A, Liska J, Nielsen LB, Gåfvels M, Mannila MN, Hamsten A, Yki-Järvinen H, Thelle D, Eriksson P, Borén J, Ehrenborg E: Allele-specific regulation of MTTP expression influences the risk of ischemic heart disease. J Lipid Res 2010, 51:103-111.

27. Hagan DL, Kienzle B, Jamil H, Hariharan N: Transcriptional regulation of human and hamster microsomal triglyceride transfer protein genes. Cell type-specific expression and response to metabolic regulators. J Biol Chem 1994, 269:28737-28744.

28. Sato R, Miyamoto W, Inoue J, Terada T, Imanaka T, Maeda M: Sterol regulatory element-binding protein negatively regulates microsomal triglyceride transfer protein gene transcription. J Biol Chem 1999, 274:24714-24720.

29. Boeing H, Korfmann A, Bergmann MM: Recruitment procedures of EPIC germany: european investigation into cancer and nutrition. Ann Nutr Metab 1999, 43:205-215.

30. Boeing $\mathrm{H}$, Wahrendorf J, Becker N: EPIC-germany-a source for studies into diet and risk of chronic diseases. European investigation into cancer and nutrition. Ann Nutr Metab 1999, 43:195-204.

31. Bergmann MM, Bussas U, Boeing H: Follow-up procedures in EPIC germany- data quality aspects: european prospective investigation into cancer and nutrition. Ann Nutr Metab 1999, 43:225-234.

32. Rundle $A G$, Vineis $P$, Ahsan $H$ : Design options for molecular epidemiology research within cohort studies. Cancer Epidemiol Biomarkers Prev 2005, 14:1899-1907

33. Weikert C, Stefan N, Schulze MB, Pischon T, Berger K, Joost HG, Härung HU, Boeing $H$, Fritsche A: Plasma fetuin-A levels and risk of myocardial infarction and ischemic stroke. Circulation 2008, 118:2555-2562.

34. Prentice R: A case-cohort design for epidemiologic cohort studies and disease prevention trials. Biometrika 1986, 73:1-11.

35. Miettinen O: Design options in epidemiologic research. An update. Scand J Work Environ Health 1982, 8:7-14

36. Weikert C, Berger K, Heidemann C, Bergmann MM, Hoffmann K, KlipsteinGrobusch K, Boeing $\mathrm{H}$ : Joint effects of risk factors for stroke and transient ischemic attack in a german population: the EPIC potsdam study. J Neurol 2007, 254:315-321.
37. Schmermund A, Möhlenkamp S, Stang A, Grönemeyer D, Seibel R, Hirche H, Mann K, Siffert W, Lauterbach K, Siegrist J, Jöckel KH, Erbel R: Assessment of clinically silent atherosclerotic disease and established and novel risk factors for predicting myocardial infarction and cardiac death in healthy middle-aged subjects: rationale and design of the heinz nixdorf RECALL study. Risk factors, evaluation of coronary calcium and lifestyle. Am Heart 2002, 144:212-218

38. Nomenclature and criteria for diagnosis of ischemic heart disease. Report of the joint international society and federation of cardiology/ world health organization task force on standardization of clinical nomenclature. Circulation 1979, 59:607-609. http://www.ncbi.nlm.nih.gov/ pubmed/761341.

39. Alexander RW, Pratt CM, Roberts R: Diagnosis and management of patients with acute myocardial infarction. In Hurst's The Heart, Arteries and Veins. Edited by Alexander RW, Schlant RC, Fuster V. McGraw-Hill: New-York; 1998:1345-1433.

40. Bohlscheid-Thomas S, Hoting I, Boeing H, Wahrendorf J: Reproducibility and relative validity of food group intake in a food frequency questionnaire developed for the german part of the EPIC project. European prospective investigation into cancer and nutrition. Int $J$ Epidemiol 1997, 26(Suppl 1):S59-S70.

41. Expert panel on detection, evaluation, and treatment of high blood cholesterol in adults. Executive summary of the third report of the national cholesterol education program (NCEP) expert panel on detection, evaluation, and treatment of high blood cholesterol in adults (adult treatment panel III). JAMA 2001, 285:2486-2497. http://www.ncbi. nlm.nih.gov/pubmed/11368702.

42. Andersson T, Alfredsson L, Källberg H, Zdravkovic S, Ahlbom A: Calculating measures of biological interaction. Eur J Epidemiol 2005, 20:575-579.

43. Rothman KJ: The estimation of synergy or antagonism. Am J Epidemiol 1976, 103:506-511.

44. Lunn M, McNeil D: Applying Cox regression to competing risks. Biometrics 1995, 51:524-532.

45. Gauderman WJMJ: QUANTO 1.1: A computer program for power and sample size calculations for genetic-epidemiology Studies; 2006. http://hydauscedu/ gxe Last accessed: August 2012.

46. Nordestgaard BG, Benn M: Fasting and nonfasting LDL cholesterol: to measure or calculate? Clin Chem 2009, 55:845-847. doi:10.1373/ clinchem.2008.123083.

47. Joy TR, Hegele RA: Microsomal triglyceride transfer protein inhibitionfriend or foe? Nat Clin Pract Cardiovasc Med 2008, 5:506-508.

\section{doi:10.1186/1471-2350-14-19}

Cite this article as: di Giuseppe et al:: Microsomal triglyceride transfer protein $-164 \mathrm{~T}>\mathrm{C}$ gene polymorphism and risk of cardiovascular disease: results from the EPIC-Potsdam case-cohort study. BMC Medical Genetics 2013 14:19.

\section{Submit your next manuscript to BioMed Central and take full advantage of:}

- Convenient online submission

- Thorough peer review

- No space constraints or color figure charges

- Immediate publication on acceptance

- Inclusion in PubMed, CAS, Scopus and Google Scholar

- Research which is freely available for redistribution 